\title{
La prevención integral en población consumidora de sustancias psicoactivas*
}

LydaPérez Acevedo**

Esta ponencia reúne una propuesta de acción que en principio fue presentada para afrontar el problema del consumo de sustancias psicoactivas por parte de los estudiantes de la Universidad Nacional y que actualmente guía el subprograma "Recuperación psicosocial de población consumidora de sustancias psicoactivas -habitante de la calle", el cual hace parte del Programa Académico de Campo: Desempeño Ocupacional y Bienestar Psicosocial de la carrera de Terapia Ocupacional de la Universidad Nacional de Colombia.

El fenómeno de las drogas ha permanecido por largo tiempo en la historia del hombre acompañándolo a través de su propia evolución. Y al igual que la música, la guerra o la ciencia, es uno de los productos de la creación humana que ofrece un camino para construir su propio ser. Camino que para algunos incrementa su calidad de vida y brinda las satisfacciones y apegos que su entorno social, familiar $y$ cultural no provee.

El entorno en el cual se desarrolla este fenómeno carece de limites espaciales y temporales, se concibe como universal, afecta a todos sin distingo de raza, sexo, edad o condición socioeconómica y hace parte de otra diversidad de problemas asociados a éste como lo son la delincuencia, la violencia y el pandillismo entre otros.

La dimensión de este problema exige una visión amplia y diversa en torno a su origen cultural, donde esta problemática tiene sus orígenes y, por ende, en el único

\footnotetext{
* Ponencia XII Congreso Colombiano de T.O. Santa Marta; 2001.

** Terapeuta Ocupacional. Profesora Asistente Universidad Nacional. Marzo de 2001.
} 
ámbito desde el cual es posible desarraigarla: en el escenario de los hábitos, las costumbres y las prácticas sociales que definen la cotidianidad de individuos y grupos, la cultura y los lugares comunes de nuestra sociedad.

Para entender el fenómeno de las drogas y desarrollar estrategias acertadas es necesario el trabajo coordinado de los miembros de la comunidad, de modo que se identifiquen los procesos sociales, culturales, educativos, económicos e individuales alrededor de los cuales gira, se mantiene y se incrementa el problema de las drogas.

Dada la diversidad de orientaciones teóricas que han guiado las estrategias de intervención en este problema, se requiere de la participación interdisciplinaria para el diseño y/o adaptación de un modelo teórico que facilite el ordenamiento y coherencia entre los diferentes enfoques, criterios y acciones dirigidas a la promoción y prevención de la farmacodependencia.

A partir del modelo establecido es posible determinar los procesos básicos alrededor de los cuales gira el problema del uso indebido de sustancias, las estrategias a desarrollar, las áreas de intervención y los actores de dicha estructura.

Alrededor de los modelos teóricos, es necesario conocer y analizar los diversos modelos de prevención que sustentan diferentes conceptos; métodos y enfoques.

1. MODELODE SALUD PÚBLICA: Incluye los conceptos de prevención primaria, secundaria y terciaria.

$\checkmark$ Prevención Primaria Comprende la promoción de la salud y la protección específica.

$\checkmark$ Prevención Secundaria Comprende el diagnóstico precoz y tratamiento oportuno

$\checkmark$ Prevención Terciaria: La prevención terciaria está conformada por la limitación del daño y la rehabilitación

2. MODELO DE LASNACIONES UNIDAS: Plantea que las acciones preventivas deben incluir los tres factores: individuo, droga y medio ambiente.

3. MODELO LEGAL: Modelo que se orienta a la oferta, controlando el acceso a las drogas, su posesión o uso, por medio de prescripción médica o sanciones. 
4. MODELO HOLÍSTICO: Este modelo incluye los elementos de protección y promoción de la salud dentro de la esfera de la prevención. La protección implica los esfuerzos por proteger los riesgos que ponen en peligro la salud y la promoción se refiere al desarrollo de actividades que promueven estilos de vida más saludables.

5. MODELO DEL INSTITUTO NACIONAL DE ABUSO DE DROGAS (NIDA): Plantea acciones en cinco niveles o componentes: Normativo, Informativo, Educativo, de Alternativas y de Intervención específica.

6. MODELO PREVENTIVO GENERAL: Plantea acciones en los tres niveles de la salud publica e incluye los componentes expuestos en el modelo NIDA.

7. SISTEMA PLURIMODAL PARA LA PREVENCIÓN DEL ABUSODEDROGAS DURANTE TODA LA VIDA: Incluye objetivos específicos y estrategias de trabajo para cada grupo de edad. Incluyen programas que se enfocan en el estilo de vida, en el ambiente, en los servicios humanos y en los reglamentos legales.

8. PREVENCIÓN INTEGRAL: Enfocada en la promoción del desarrollo humano, individual y colectivo a partir de las propias potencialidades.

Una vez analizados los anteriores modelos es posible identificar tres enfoques teóricos-básicos relacionados con los esfuerzos preventivos en el área de prevencióneducación:

- Conocimientos-actitudes: Enfoque de información, basado en la suposición de que el conocimiento sobre drogas afectará las actitudes y el comportamiento.

- Valores-toma de decisiones: Este enfoque trata de promover el conocimiento de sí mismo y el desarrollo de una actitud responsable para la toma de decisiones.

- Competencias sociales: Propone que la comunicación y las relaciones interpersonales proporcionan las destrezas sociales necesarias para resistir influencias sociales que comprometan la integridad personal. 


\section{LA PREVENCIÓN INTEGRAL COMO PROCESO DE RECONSTRUCCIÓN CULTURAL}

La perspectiva más recientes en el abordaje de la farmacodependencia señala la importancia de una visión más comprensiva y actuante, basada en la participación comunitaria y la movilización de redes de afecto y solidaridad, haciendo énfasis en el fortalecimiento de las potencialidades propias de las personas, para reducir su vulnerabilidad y ampliar su capacidad de respuesta autónoma frente a los factores de riesgo asociados a la drogadicción y otros problemas conexos.

Asumiendo la droga como un producto cultural, este enfoque preventivo despliega su acción allí donde la problemática tiene sus raíces y, por ende, en el único ámbito desde el cual es posible desarraigarla: el escenario de los hábitos, las costumbres y las practicas sociales que definen la cotidianidad de individuos y grupos, la cultura, los lugares comunes de nuestra sociedad.

Principales elementos que definen y caracterizan a la prevención integral:

1. La farmacodependencia es un fenómeno que aparece en el ámbito social de la persona, y más específicamente, en la esfera de su cotidianidad y sù interactuar con los demás.

2. La farmacodependencia es la expresión abierta de una trama de conflictos y crisis vinculados a las situaciones de la vida diaria que es preciso confrontar, ya que en ellas radica la verdadera naturaleza de la problemática que se pretende evitar.

3. La acción preventiva debe estar orientada a contrarrestar o evitar los factores causales asociados al problema y no sólo a combatir las manifestaciones de dicho problema.

4. La superación del problema de la droga, está condicionada por las respuestas que se den frente a las condiciones que ocasionan o agudizan dicho problema. La acción preventiva debe ocuparse no solo de la drogadicción como problema en sí, sino además de las inter-relaciones y nexos entre este y otros problemas (violencia familiar, fracaso escolar, marginamiento social, etc.).

5. La acción preventiva debe desarrollarse directamente EN el contexto social en el que están inmersas las personas y $\mathrm{CON}$ la propia colectividad de la que ellas hacen parte. 
6. La prevención integral propone oponer los factores culturales asociados a la problemática objeto de prevención, unas condiciones de desarrollo cultural alternativo.

7. La acción preventiva debe centrar la atención en las potencialidades de las personas, en sus propios recursos y capacidades, antes que en sus carencias y debilidades.

8. Las estrategias preventivas hacen referencia a la creatividad, el afecto, la comunicación, la alegría, a brindar espacios de sensibilidad, imaginación y expresividad.

9. La prevención integral es la actuación colectiva y co-responsable de profesionales especializados, funcionarios, líderes, educadores, padres de familia, jóvenes y comunidad en general, en el marco de una relación horizontal y cogestiva.

10. La problemática del abuso de las drogas debe ser encarada desde una perspectiva global, totalizante, en la que concurren distintos saberes y frentes de acción; es decir, mediante un abordaje multidisciplinario e intersectorial.

Esta orientación de la prevención integral actualmente sustenta acciones terapéuticas de prevención inespecífica tendientes al desarrollo de hábitos de vida, estilos de vida saludable, utilización productiva del tiempo libre, producción cultural y reconstrucción del proyecto de vida, desarrolladas en el Programa Académico de Campo: "Recuperación psicosocial de población consumidora de sustancias psicoactivas-habitante de la calle", que se realiza en una comunidad terapéutica dedicada a la rehabilitación de personas adultas consumidoras de sustancias psicoactivas.

En dicha práctica se encuentran en desarrollo dos proyectos (cultural y deportivo), que soportados en la teoría de la prevención integral retoman las habilidades presentes, potencian las posibilidades de crecimiento, resaltan los valores conservados, ofrecen la posibilidad de tomar decisiones y sustentar ideas... pero la pregunta que surge es: ¿Cómo un proyecto deportivo y uno cultural puede traducirse en acciones preventivas? La respuesta se resume en el siguiente cuadro. 


\section{LA CONSTRUCCIÓN CULTURAL A TRAVÉS DE LA OCUPACIÓN}

\begin{tabular}{|c|c|c|}
\hline $\begin{array}{l}\text { Componentes } \\
\text { del proceso cultural }\end{array}$ & $\begin{array}{c}\text { Capacidades y valores } \\
\text { asociados a los procesos } \\
\text { culturales }\end{array}$ & $\begin{array}{c}\text { Resultados esperados en } \\
\text { conductas dé prevénción } \\
\text { : . }\end{array}$ \\
\hline $\begin{array}{l}\text { 1. Producción cultural: } \\
\text { - Identificación de intere- } \\
\text { ses. } \\
\text { - Desarrollo de iniciativas } \\
\text { - Generación de idea. } \\
\text { - Realización de los pro- } \\
\text { ductos culturales. } \\
\text { - Análisis de contextos. }\end{array}$ & $\begin{array}{l}\text { - Trabajo en grupo } \\
\text { - Disciplinà } \\
\text { - Cumplimiento } \\
\text { - Creatividad } \\
\text { - Juicio }\end{array}$ & $\begin{array}{l}\text { - Autoestima } \\
\text { libre. } \\
\text { - Solidaridad } \\
\text { - Responsabilidad } \\
\text { - Tolerancia } \\
\text { - Respeto al otro }\end{array}$ \\
\hline $\begin{array}{l}\text { 2. Transmisión cultural: } \\
\text { : Ubicación de lugares y } \\
\text { receptores. } \\
\text { - Manejo de la imagen. }\end{array}$ & $\begin{array}{l}\text { - Competitividad } \\
\text { - Acceso a públicos }\end{array}$ & $\begin{array}{l}\text { - Perseverancia } \\
\text { - Interdependencia social } \\
\text { - Tolerancia a la frustráción } \\
\text { - Logro }\end{array}$ \\
\hline $\begin{array}{l}\text { 3. Sustento financiero de las } \\
\text { propuestas culturales: } \\
\text { - Identificación de fuentes } \\
\text { de financiación. } \\
\text { - Acceso a fuentes. } \\
\text { - Inversión cultural. }\end{array}$ & $\begin{array}{l}\text { - Planeación } \\
\text { - Venta de servicios } \\
\text { - Juicio de realidad }\end{array}$ & $\begin{array}{l}\text { - Organización } \\
\text { - Autocontrol } \\
\text { - Autonomía, } \\
\text { - Autogratificación } \\
\text { - Estabilidad }\end{array}$ \\
\hline $\begin{array}{l}\text { 4. Gestión administrativa: } \\
\text { - Diseño, gestión, control } \\
\text { y evaluación de los pro- } \\
\text { yectos. } \\
\text { - Estudios de factibilidad, } \\
\text { de costos. }\end{array}$ & $\begin{array}{l}\text { - Capacidad de planeación, } \\
\text { gestión, control y evaluación } \\
\text { - Organización. } \\
\text { - Capacidad de análisis y } \\
\text { planeación. }\end{array}$ & $\begin{array}{l}\text { - Manejo racional del } \\
\text { tiempo. } \\
\text { - Responsabilidad } \\
\text { - Interdependencia social }\end{array}$ \\
\hline
\end{tabular}

Retomando algunas reflexiones de Luis Angel Parra ${ }^{1}$ estudioso del tema de la prevención integral, es bastante factible asegurar que el problema de la droga nos va acompañar durante mucho tiempo y es realmente compromiso de todos consolidar una CULTURA DE LA PREVENCION INTEGRAL, entendida más alla de la enfermedad, más alla de la remediación de los problemas, que involucre bienestar y desarrollo. "En otras palabras, la labor preventiva incluye lo promocional y lo esen-

\footnotetext{
${ }^{1}$ Parra, L. Reflexiones acerca del fenómeno cultural de la droga y de la prevención integral. Mininsterio de Educación. 1994.
} 
cial de lo promocional es que no se limita a neutralizar o advertir sobre los péligroso, sino que tiene como tarea y compromiso estimular la vida plena"2.

La invitación implica entonces repensar la forma como nos enfrentamos a la persona que consume drogas, quizas hemos esperado menos de ellos, limitando sus posibilidades. En ocasiones se observa como el terapeuta ocupacional prepara un arsenal de estrategias terapeuticas, donde la persona apenas es un sujeto pasivo que sigue cada una de las preelaboradas estrategias. Bajo ese enfoque es poco factible pensar en aquellos resultados que miden la efectividad: reinserción laboral, social, familiar; bajo ese enfoque la acción terapéutica se acerca mucho más a las palabras reingreso y recaida.

Planteo a continuación una propuesta de cómo, por ejemplo, las universidades pueden desarrollar estrategias de prevención integral desde la docencia, la investigación y la extensión. Cabe aclarar que esta propuesta es aplicable a cualquier colectivo (barrios, colegios, insituciones, comunidades tearpeuticas...)

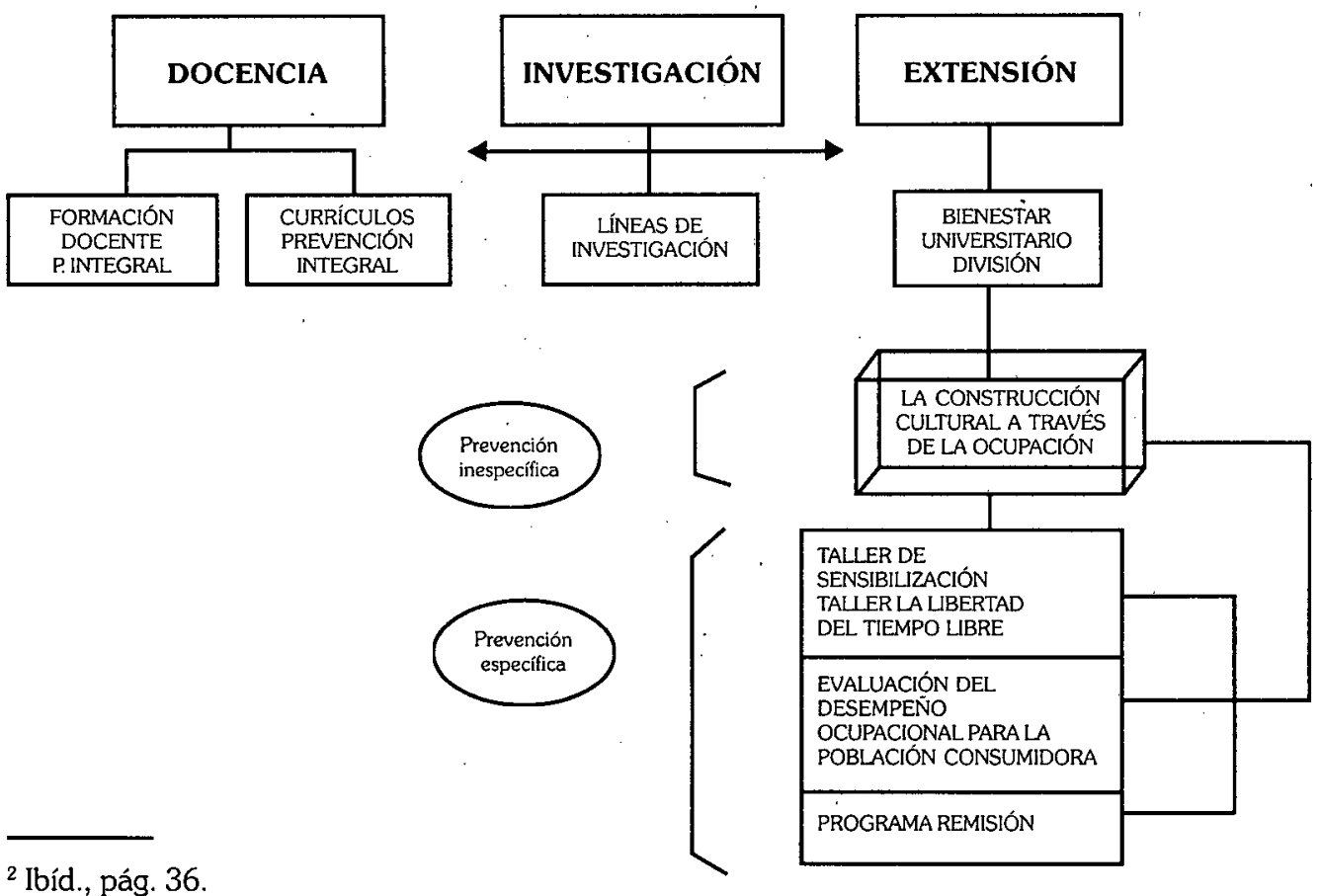




\section{BIBLIOGRAFÍA}

- Cultura, juventud y arte. Serie Prevenir es construir futuro $N^{\circ} 4$. Alcaldía Mayor de Santa Fe de Bogotá. Unidad Coordinadora de Prevención Integral. 1994.

- La droga en el espejo de la cultura. Serie Prevenir es construir futuro $\mathrm{N}^{\circ} 6$. Álcaldía Maýór de Santa Fe de Bogotá. Unidad Coordinadora de Prevención Intéǵral. 1994:

- Ministerio de Salud. Manual regional de educación preventiva participativa para jóvenes y padres. Programa de prevención las farmacodependencias. Instituto interamericano del niño. 1996.

- Parra, L. Reflexiones acerca del fenómeno cultural de la droga y de la prevención integral. Ministerio de Educación. 1994.

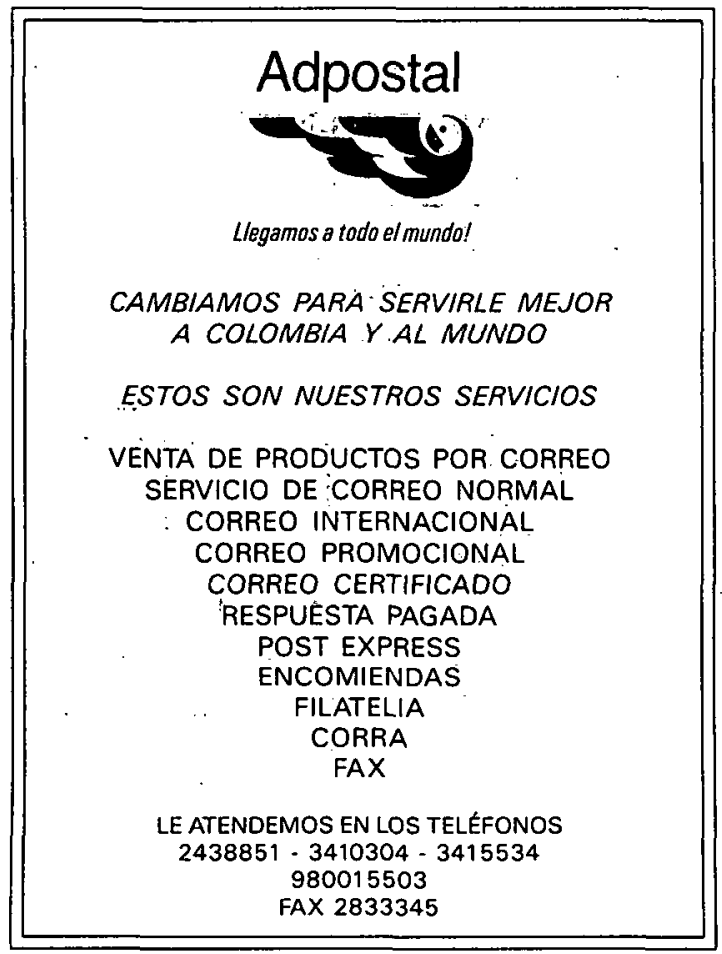

